\begin{tabular}{|c|c|}
\hline & $\begin{array}{l}\text { International Journal of Trend in Scientific } \\
\text { Research and Development (IJTSRD) }\end{array}$ \\
\hline 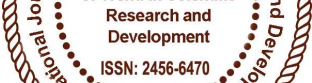 & International Open Access Journal \\
\hline 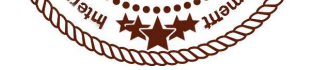 & ISSN No: 2456 - 6470 | www.ijtsrd.com | Volume - 2 | Issue - 2 \\
\hline
\end{tabular}

\title{
Role of Information \& Communication Technology in Developing the Banking Sector of India
}

\author{
Smt Paramita Chatterjee \\ Govt. Approved Contractual Whole Time Teacher \\ Department of Computer Science, Charuchandra \\ College, University of Calcutta, Kolkata, India
}

\section{ABSTRACT}

Today Information\& Communication Technology is not only for computer literacy, it also deals with how computers work and how these computers can further be used not just for information processing but also for communications and problem solving tasks as well. The significance of ICT can be seen from the fact that it has penetrated almost every aspect of our daily lives from business to leisure and even society and social development. The $21^{\text {st }}$ century will bring about an all-embracing convergence of computing, communications and informations. This explosion of technology is changing the banking industry from paper and branch banks to digitized and networked banking services. All over the world, banks are still struggling to find a technological solution to meet the challenges of a rapidly-changing environment. The present article presents the role of Computer Science as well as Information\& Communication Technology in developing the banking industry in India.

Keywords: ICT, Computer Science, e-banking, Services

\section{Introduction}

ICT is the study, design, development, implementation, support or management of computer based information systems, particularly software applications and computer hardware. IT is the use of electronic computers and computer software to convert, store, protect, process, transmit and securely retrieve information. Information technology is thus nothing but combination of computers and communication technology. The term Information Technology (IT) was coined by Jim Domsic of Michigan in November 1981, who created the term to modernize the outdated phrase "data processing".[5]

Information technology (IT), defined by the Information technology Association of America (ITAA) is a general term that describes any technology that helps to produce, manipulate, store, communicate, and/ or disseminate information.

Today information technology is not only for computer literacy, it also deals with how computers work and how these computers can further be used not just for information processing but also for communications and problem solving tasks as well. Today personal PCs, cell phones, fax machines, pagers, email and internet have all not only become an integral part of our culture but also play an essential role in our day to day activities. IT professionals perform a variety of duties that range from installing applications to designing complex computer networks and information databases. A few of the duties that IT professionals perform may include data management, networking, engineering computer hardware, database and software design, as well as the management and administration of entire systems. Information technology has a major role to play:

\section{Role of computerization}

2. Role of information management

3. Role of communication technology 
Components of Information Technology:

1. Computer Hardware Technologies: These technologies include processors, storage devices, input and output devices etc.

2. Computer Software Technologies: These technologies include operating system software, web browsers, software productivity suits and software for business applications.

3. Data Resource Management Technologies: These technologies include database management system software for the development, access and maintenance of the databases of an organization.

\section{Telecommunication and Network Technologies:} These technologies include telecommunication media, processors and software needed to provide wire-based and wireless access and support for Internet and other networks.

\section{Literature review:}

After its invention Computer has changed the working of many industries, banking is one of those industries where its introduction has changed the whole style of operation. Earlier banking was bulky, heavy and cumbersome because mode of operation was manual. Banks used to maintain big ledgers, maintaining which was a herculean job. So, operation was slow, not user friendly and the whole banking system was not accessible to the common man. But after introduction of computer the scenario has entirely changed. [4]

The concept of bank automation in India started in the period 1984-1987 based on "first Rangarajan committee report" in 1984. However the speed of bank automation was very slow. Another committee was constituted under the chairmanship of C. Rangarajan, the then deputy governor of RBI in 1988 to slate down a plan on automation of banks. This paved the way for the implementation of multi user total branch automation packages running on a LAN, either on a NetWare or a UNIX operating system. After economic liberalization in 1991 new private sector banks started their business. With the introduction of new private sector banks the real era of bank marketing started and they offered their customers anywhere any time banking. The reason behind their giving these services to their customers was they opted for the implementation of WAN
(Wide Area Network) based centralized banking solution rather than a LAN based banking solution. With improved telecommunication systems and reduction in the price of hardware and network solutions the banks in India opted for CBS or core banking solution. Under core banking solution every bank branch in India is connected to a single server enabling the process of banking much easier than earlier.

The result of computerization in the banking sector and its automation was many fold. It helped in better customer service, flawless book keeping and prompt decision making which improved in profitability and productivity. With the introduction of card facilities the customer of a bank need not carry cash. With the introduction of ATM bank customers need not visit their bank branch very often which saved a lot of time of the customers and for the banks. With the increase of use of computer now electronic payment system like NEFT and RTGS has become very popular. Now everything has become very fast starting from account opening to payment services. Recently in 2014 our government launched a very ambitious project called PMJDY to bring every man under banking. Under this scheme 22.37 crore accounts were open. Without computerization it would have never been possible.

The introduction of computer has changed the working of some of the old instruments in the banking sector like cheque. Now after introduction of cheque truncation system the physical movement of the cheque has been stopped rather the beneficiary bank now sends a scanned image of the cheque to the banker of the payer and the cheque is cleared on the basis of that image. This system has made the use of cheque much more convenient, fast and cheap as the banks do not send the physical cheque it saves the transit time and the money involved inthe transit and it enables the cheque to be cleared very fast usually within two days[1].

Now those who do not prefer standing in a long queue of a bank prefers banking from their home. With the rapid introduction of technology now it is possible to bank from our homes all we need a computer and an Internet connection. Internet banking has changed the way we used to bank. By using internet banking we can transfer money whenever we need, ask for cheque books, pay our bills online, do fixed deposits, can generate account statements, stop payment of cheque, and can do many more things. Besides Internet 
banking mobile banking is also getting popular especially after smartphones introduced. Now we are using mobile wallets for recharging our mobiles, bill payment, and payment of cab services. Now in a new development the way we undertake money transaction in India is expected to change dramatically with the introduction of Unified Payment Interface (UPI). The main objective behind the introduction of UPI is to achieving the goal of a lower cash intensive society. The thinking behind the UPI was to make the application as simple as possible. Paying and receiving money should be as easy as making a phone call or sending a message. An account holder should be able to send or receive money with their mobile phone with just an identifier without having any other details like bank/account details. This interface is going to be a game changer in mobile banking.

\section{Information\& Communication Technology Tools in Banking Sector:}

3.1 Internet: Internet is a networking of computers. In this networking message can be transferred and received worldwide. The data can be sent and received in any part of the world. In short time, internet facility can do many job for us. It includes the following:

1. This net can work as electronic mailing system.

2. It can have access to the distant database, which may be a newspaper of foreign country.

3. We can exchange our ideas through Internet. We can make contact with anyone who is a linked with internet. On internet, we can exchange letters, figures/diagrams and music recording.

Internet is a fast developing net and it is most important for public sector undertaking, Educational Institutions, Research Organization etc.

Banks are aware of customer's need for new services and plan to make them available. IT has increased the level of competition and forced them to integrate the new technologies in order to satisfy their customers. They have already developed and implemented a certain number of solutions among them:

Self-inquiry facility: Facility for logging into specified self-inquiry terminals at the branch to inquire and view the transactions in the account.

Remote banking: Remote terminals at the customer site connected to the respective branch through a modem, enabling the customer to make inquiries regarding his accounts, on-line, without having to move from his office.

Anytime banking-Anywhere banking: Installation of ATMs which offer non-stop cash withdrawal, remittances and inquiry facilities. Networking of computerized branches inter-city and intra-city will permit customers of these branches, when interconnected, to transact from any of these branches.

Telebanking: A 24-hour service through which inquiries regarding balances and transactions in the account can be made over the phone.

\subsection{Phone Banking and Mobile Banking}

Phone and mobile banking are a fairly recent phenomenon for the Indian banking industry. There exist operative guidelines and restrictions on the type and quantum of transactions that can be undertaken via this route. Phone banking channels function through an Interactive Voice Response System (IVRS) or telebanking executives of the banks. The transactions are limited to balance enquiries, transaction enquiries, stop payment instructions on cheques and funds transfers of small amounts (per transaction limit of Rs 2500, overall cap of Rs 5000 per day per customer). According to the draft guidelines on mobile banking, only banks which are licensed and supervised in India and have a physical presence in India re allowed to offer mobile banking services. Besides, only rupee based services can be offered. Mobile banking services are to be restricted to bank account and credit card account holders which are $\mathrm{KYC}$ and $\mathrm{AMC}$ compliant.

3.2.1 Electronic Banking: This enables the bank to provide corporate or high value customers with GraphicalUser Interface (GUI) software on a PC, to inquire about their financial transactions and accounts, cash transfers, cheque book issue and inquiry on rates without visiting the bank. Moreover, LC text and details on bills can be sent by the customer, and the bank can download the same. The technology used to provide this service is called electronic data interchange (EDI). It is used to transmit business transactions in computer-readable form between organizations and individuals in a standard format. 
3.2.3 Electronic Clearing Service: The Electronic Clearing Service (ECS) introduced by the RBI in 1995, is akin to the Automated Clearing House system that is operational in certain other countries like the US. ECS has two variants- ECS debit clearing and ECS credit clearing service. ECS credit clearing operates on the principle of 'single debit multiple credits' and is used for transactions like payment of salary, dividend, pension, interest etc. ECS debit clearing service operates on the principle of 'single credit multiple debits' and is used by utility service providers for collection of electricity bills, telephone bills and other charges and also by banks for collections of principal and interest repayments. Settlement under ECS is undertaken on $\mathrm{T}+1$ basis. Any ECS user can undertake the transactions by registering themselves with an approved clearing house. [3]

- As information is centralized and updates are available simultaneously at all places, singlewindow service becomes possible, leading to effective reduction in waiting time.

During the last decade, banks applied IT to a wide range of back and front office tasks in addition to a great number of new products. The major advantages for the bank to implement IT are:

- Availability of a wide range of inquiry facilities, assisting the bank in business development and follow-up.

- Immediate replies to customer queries without reference to ledger-keeper as terminals are provided to Managers and Chief Managers.

- Automatic and prompt carrying out of standing instructions on due date and generation of reports.
- Generation of various MIS reports and periodical returns on due dates.

Fast and up-to-date information transfer enabling speedier decisions, by interconnecting computerized branches and controlling offices.

3.3 Satellite Banking: Satellite banking is also an upcoming technological innovation in the Indian banking industry, which is expected to help in solving the problem of weak terrestrial communication links in many parts of the country. The use of satellites for establishing connectivity between branches will help banks to reach rural and hilly areas in a better way, and offer better facilities, particularly in relation to electronic funds transfers. However, this involves very high costs to the banks. Hence, under the proposal made by RBI, it would be bearing a part of the leased rentals for satellite connectivity, if the banks use it for connecting the north eastern states and the under banked districts.[7]

3.4 Technology Vendors: Many Indian banks handled technological issues in house till the late 1990s. Thereafter, the complications of the business necessitated the engagement of specialized vendors to handle complex issues. Due to the complexities involved, most banks now prefer to engage IT vendors to introduce specialized softwares to help in their risk management systems, retail and corporate banking, card management systems, complete back office support including data management systems [7].

\section{Table 1: Major Technology Vendors \& Products}

\begin{tabular}{|c|c|}
\hline Vendor & Flagship products and applications \\
\hline $\begin{array}{ll}\text { i-flex Solutions } \\
\text { (Oracle } & \text { Financial } \\
\text { Services } & \text { Software } \\
\text { limited) } & \end{array}$ & $\begin{array}{l}\text { - Flexcube-core banking solutions, ,retail, corporate, internet banking, } \\
\text { investor servicing and asset management } \\
\text { - Other offering include Flexcube lending suite, Flexcube for Islamic banking, } \\
\text { private banking } \\
\text { - Reveleus -risk management solutions } \\
\text { - Mantas-risk and compliance solutions }\end{array}$ \\
\hline Infosys & $\begin{array}{l}\text { - Finacle-core banking solutions } \\
\text { - E-banking } \\
\text { - CRM } \\
\text { - Treasury } \\
\text { - Cash Management } \\
\text { - Wealth Management } \\
\text { - Islamic Banking } \\
\end{array}$ \\
\hline
\end{tabular}




\begin{tabular}{|c|c|}
\hline TCS & $\begin{array}{l}\text { - TCS BaNCS suit of solutions covering banking } \\
\text { - } \quad \text { Capital Market and Insurance Firms } 28.5\end{array}$ \\
\hline Nucleus Software & $\begin{array}{l}\text { - } \text { Finone-Comprehensive suit of software for retail banking applications } \\
\text { - } \text { Cash@will-Cash Management } \\
\text { - Trade Facto-Trade Finance } \\
\text { - BankOnet-Internet banking } \\
\text { - PowerCard-Credit Cards } \\
\text { - } \quad \text { FMS-Fraud Management System }\end{array}$ \\
\hline
\end{tabular}

Source: D\&B Industry Research Service

3.5 Unified Payments Interface (UPI): This is an instant real-time payment system developed by National Payments Corporation of India facilitating inter-bank transactions. The interface is regulated by the Reserve Bank of India and works by instantly transferring funds between two bank accounts on a mobile platform.

UPI is built over Immediate Payment Service (IMPS) for transferring funds. Being a digital payment system it is available $24 * 7$ and across public holidays. Unlike traditional mobile wallets, which take a specified amount of money from user and stores it in its own

Table 2: [13]

\begin{tabular}{|l|}
\hline \multicolumn{2}{|c|}{ Financial Services } \\
\hline Fund Transfer \\
- Send Money \\
- Request Money ISS \\
\hline
\end{tabular}

\subsubsection{Transaction Charges}

The transaction charges to be levied in UPI are left up to the banks as policy matter of individual banks. So a varied opinion exists among the bankers about imposing such charges. Many bankers feel that imposing transaction charges will hamper UPI adoption.

- HDFC bank has held its decision about charging its customers for UPI transactions

- SBI has proposed charging for UPI transaction in future.

Table 3:[13]

\begin{tabular}{|l|l|}
\hline Bank & Charges \\
\hline ALL Banks & 0 \\
\hline
\end{tabular}

2.Change MPIN accounts, UPI withdraws and deposits funds directly from the bank account whenever a transaction is requested. It uses Virtual Payment Address (a unique ID provided by the bank), Account Number with IFS Code, Mobile Number with MMID (Mobile Money Identifier), Aadhaar Number, or a one-time use Virtual ID. An MPIN (Mobile banking Personal Identification number) is required to confirm each payment.

3.5.1 USSD Services: UPI is also available as a USSD service and users can access the service by dialing the code*99\#. The various services provided in USSD mode are categorized as follows,

\section{Non-financial services}

1.Balance enquiry

\section{Table 4: TransactionStatistics [13]}

\begin{tabular}{|l|l|l|}
\hline Year & $\begin{array}{l}\text { Transaction Amount } \\
\text { (tens of billion rupees) }\end{array}$ & Growth \\
\hline 2016 & 0.894053 & - \\
\hline 2017 & 56.76170 & $6248.81 \%$ \\
\hline
\end{tabular}

\section{Digital Banking\& Financial Inclusion:}

This is the move to online banking where banking services are delivered over the internet. The advantages for banks and customers are providing more convenient and faster banking services. The shift from traditional to digital banking has been gradual and should be rather described in degrees of service digitization than through a categorization into yes and no. It involves high levels of process automation and web-based services and may include 
APIs enabling cross-institutional service composition to deliver banking products and provide transactions. It provides the ability for users to access financial data through desktop, mobile_and ATM services[8].

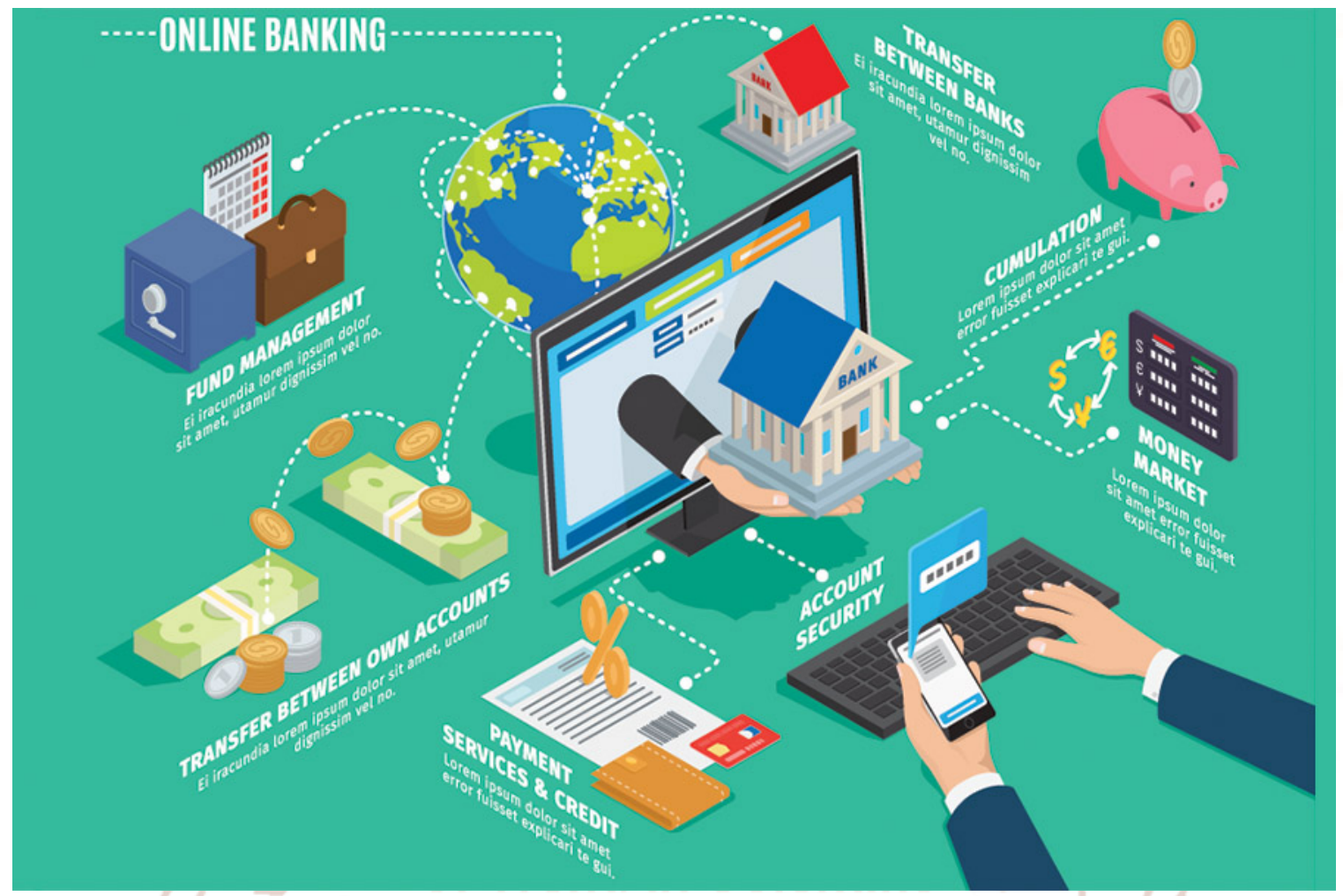

Figure 1: Digital Banking [12]

\subsection{Financial Inclusion: "Digital financial} inclusion" can be defined as digital access to and use of formal financial services by excluded and underserved populations. Such services should be suited to the customers' needs and delivered responsibly, at a cost both affordable to customers and sustainable for providers. With the prospect of reaching billions of new customers, banks and nonbanks have started to offer digital financial services for financially excluded and underserved populations, building on the approaches which have been used for years to improve access channels for those already served by banks and other financial institutions. Innovative digital financial services associated with the use of mobile phones have been launched in more than 80 countries (GSMA 2014). As a result of the significant advances in the accessibility and affordability provided by digital financial services, millions of poor customers are moving from exclusively cash-based transactions to formal financial services. The benefits of this development include economic growth and stability, both for the customers and for the economies where they and their families reside. However, the use of digital financial services by formerly excluded customers brings not only benefits but also risks, due in part to the characteristics of a typical poor customer (inexperienced with formal financial services and unfamiliar with consumer rights). Some of the risks are new while others, although well known, may take on different dimensions in the financial inclusion context. This Brief aims have to provide national and global policy makers with a clear picture of the rapid development of digital financial services with the help of digital banking for the poor and the need for their attention and informed understanding [10].

\section{Impact of IT on Privacy}

Now at last we should talk about what are the security concerns in the present system of banking. With the rapid enhancement of technology the ways of doing frauds have also changed. There is no doubt that internet banking has become a great enabler for India but how safe those online portals are that is a cause for concern. People still hesitate to do online transactions. Some of the major concerns are hacking or getting access of account, security of data in motion, security on hostile platforms etc.. Data being 
stored in the computers is now being displayed when required through internet banking mobile banking, $\mathrm{ATM}^{\text {ee }} \mathrm{s}$ etc. All these have been given rise to the issues of privacy and confidentially of data .[6] The data processing capabilities of the computer, particularly the rapid throughput, integration, and retrieval capabilities, give rise to doubts in the minds of individuals as to whether the privacy of the individuals is being ignored. So long as the individual data items are available only to those directly concerned, everything seems to be in proper place, but the incidence of data being cross referenced to create detailed individual data gives rise to privacy problems. Most banks today have robust security measures in place. However, a lot of it still boils down to customers adopting the best practices to avoid misuse or fraud. The threats like viruses, Trojans, phishing attacks, worms, etc., and it's important to understand how each of them work. Every attack focuses on a specific set of information to corrupt or compromise a user's privacy.Each threat works in a unique way - while some try to corrupt customers' bank accounts, others may try to redirect them to a fake website to steal their login credentials (phishing). Some could initiate a fund transfer without customer's knowledge, while others could try to gain control over customer's computer to steal sensitive data. No matter what method these attacks follow, their sole objective is to steal money and information.

To avoid becoming a victim of these cyber threats, sensitive personal information must be well protected. Customers must remember that banks will never use e-mail or phone calls as a channel of communication to request for sensitive information. If one receives such e-mails allegedly from the bank, it must be reported immediately without reacting to the contents of that e-mail.

To prevent oneself from phishing attacks, one must get accustomed with bank's security measures. If there has been a change in security measures or website design, banks will usually send out notices to their customers to inform them of the change in and such changes will never be done overnight. If one finds that the website's authentication process looks different from what it used to be, they should check the website for other details by which they can verify its authenticity. A customer should also, if possible, refrain from accessing their banking information on a public or shared computer because there are several spyware in the market designed to steal sensitive information by recording key strokes. Even while accessing the banking website on one's own computer, one must always log off and clear the cache on the browser regularly to remove any transactional records[11].

With latest software solution and adapting the latest technology can solve these problems but some responsibility also must be taken by the customer. Customer should only adopt only best practices. We should change passwords periodically, should not share OTPs, should keep our passwords and PINs safe and should only use strong passwords so that it cannot be breaked. With these practices a customer can make banking more secure and use the whole advancement of technology.

\section{Banking on Social Media Platforms:}

Nowadays social media has become an important skill for all, even for those who do not even know a bit about IT. In recent years, access to social media by billions of users around the world, has led modern society and lots of people to concentrate on these kinds of Medias and also makes a considerable popularity, especially among the younger generation significantly. Knowledge of these media makes users to use these tools more useful and effective. Social Medias and their comprehensive development are Undeniable reality in the modern world. Statistics indicate growing use of social media. Today, more than 2 billion people in the world use social media. In January 2017, the use of social media has intensified in such a way that Facebook has 1.871 billion, WhatsApp a billion and Instagram 600 million active users. However, due to increasing Internet penetration and access of all communities to smart phones, tablets and mobile gadgets and also having a convenient access to programs and applications, the use of social media has grown rapidly. Overall estimates suggest that nearly two-thirds of active Internet users are active in social media activities too. The use of social media is changing its old mainstream from entertainment to the opportunity to work and trade.[9]

\section{CHALLENGES}

It has not been a smooth sailing for banks keen to jump onto the IT bandwagon. There have been impediments in the path like the obduracy once shown by trade unions who felt that IT could turn out to be a threat to secure employment. 
Increasing used of IT in banks has also brought up security concerns. The passing of IT Act has come as a boon to the banking sector and banks should now ensure to abide strictly by its covenants. An effort should be also made to cover e-business in the country's consumer's laws.

The choice of right channel, justification of IT investment on ROI, E-Governance disclosures, customers relationship management, penetration of IT in rural areas, outsourcing of IT operations are the major challenges and issues in the use of IT in banking operations.[3]

\section{Conclusion}

1. Information Technology facilitates wide and speedy services to banking sectors.

2. Private and Foreign banks use more Information Technology related banking services then public sector banks.

3. Reliable infra-structure of technology is the major constraint in implementing Information Technology in banks.

4. Impact of technology on efficient low cost data communications is same across all banks.

5. There is a strong association between competition pressure and implementation of IT in banking sector.

6. There is a strong association between more IT related services and customer preferring a bank.

7. Security concerns are the basic hindrance in using Technology related to banking services. [2]
5. Margaret Rouse (September 2005).ICT (information and communications technology -or technologies)

6. Chakrabarty K.C, "Mobile Commerce, Mobile Banking - The Emerging Paradigm", India Telecom 2009 Conference.

7. https://www.dnb.co.in/BFSISectorInIndia/BankC6 .asp

8. https://en.wikipedia.org/wiki/Digital_banking

9. https://www.finextra.com/blogposting/13785/bank ing-on-social-media-platforms

10. http://www.cgap.org/publications/digitalfinancial-inclusion

11. https://cio.economictimes.indiatimes.com/dobig/n ews/detail/1018

12. http://www.forbesindia.com/article/weschool/digit al-revolution-in-the-indian-bankingsector/47811/1

13. https://en.wikipedia.org/wiki/Unified_Payments_I nterface

\section{Reference}

1. Ghaziri Hassan(1998).Information technology in the banking sector:opportunities, threats and strategies( ddc.aub.edu.lb)

2. www.freepatentsonline.com(Nov 2007)

3. Sharma.M.C. \& Sharma Abhinav:Role of Information Technology in Indian Banking Sector:International Journal in Multidisciplinary and Academic Research(SSUMAR) Vol.2.No.1,January-February (ISSN 2278-5973)

4. Heeks,R. \&Renken.J.(2015). Investigating the potential of social network analysis in development studies,paper presented at DSA 2015 conference,Bath,7-8 Sep 